\title{
Container Sea-Rail Transport Volume Forecasting of Ningbo Port Based on Combination Forecasting Model
}

\author{
Huijun Wu, Guiyun Liu \\ Faculty of Maritime and Transportation, Ningbo University, Ningbo, 315211, China
}

\begin{abstract}
Keywords: Container sea-rail transport volume; Grey theory; RBF neural network; Grey-RBF neural network

\section{Abstract}

According to Grey theory and Radial Basis Function (Radial Basis Function, RBF)neural network forecasting method respective characteristics, based on Ningbo port container sea-rail transport volume for the original data in recent six years, Grey-RBF neural network combined forecasting model is used to predict container sea-rail transport volume development trend in the coming two years. Prediction results show that the average relative error of Grey-RBF neural network combined forecasting model predicted value and the actual value is minimum, the fitting accuracy is higher than the single GM $(1,1)$ model and RBF neural network model.
\end{abstract}

\section{Introduction}

Ningbo port is located in the Yangtze River golden waterway and the "T" type junction between the north and the south sea channel. It has highway, railway, aviation, inland waterway, pipelines and other modes of transport, and can dock the present implementation of the "silk road economic belt" and "maritime silk road in the 21st century" ( referred to as "One Belt And One Road")national strategy and development strategy of Yangtze River economic belt. It also has a good geographical advantage and development situation [1]. In 2014, Ningbo port previously has seized opportunities, speed up development and completed the container throughput of 18.65 million TEU, up 11.2\% over the last year, becoming the world's fifth largest container port. With the improvement of our country's railway transport network on the structure and function, Ningbo port is gradually promoting the construction of sea-rail intermodal transport comprehensive experimental area, the business has developed rapidly for container sea-rail intermodal transport, stepping into the superior drive, port initiative, railway interaction actively, inland linkage, and enterprise operation of the benign track. In the same year, Ningbo port has completed the container sea-rail intermodal transport volume intended target to 135,100 TEU, up $28.3 \%$ over the last year, the growth is the first one in six demonstration channels of the country. To accelerate improvement railway infrastructure construction and optimize for container sea-rail intermodal transport service network is not only beneficial to the relevant enterprises to reduce logistics costs, but also to enhance the capacity of freight and container port throughput growth, and to conducive to industrial transformation and upgrading so as to improve the service level and competitiveness and promote regional and inland economic rapid development is of great significance.

Railway freight closely tied to the local economy and enterprise development. Forecasting container sea-rail intermodal transport volume provides the basis for regional railway development plan and transport industrial business decisions. Container sea-rail intermodal transport volume is influenced by container throughput, GDP, total quantity of railway goods sent, foreign trade import and export, natural environment and national policy and many factors, which have complicated relationship. Literature [2] proposed a multivariable grey system series single forecasting model and was reasonable projections for Dalian port container sea-rail intermodal transport capacity; Literature [3] expounded complex relationship between the factors which have an influence on container sea-rail intermodal transport volume, thus constructing system dynamics (SD)models can effectively predict the container sea-rail intermodal transport volume; Literature [4,5] adopted the method of combination forecast. The former established Grey three exponential smoothing combination model to predict the Qingdao port container sea-rail intermodal transport volume, the latter is Grey-BP 
neural network combined forecasting model which is set up to predict container sea-rail intermodal transport capacity of Xiamen. This article will choose combination forecast theory and method to avoid the limitations of single forecasting model, grey RBF neural network combined forecasting model is set up to forecast container sea-rail intermodal transport capacity growth trend of Ningbo port for the next two years.

\section{Development Status}

Container sea-rail intermodal transport means a way of logistics transport that the import and export goods are transported by railway to the coastal port first in the form of container, then shipped out, or after import and export goods are delivered by ship to coastal ports, then transported by rail to inland. Sea-rail transport has a wide coverage, various business process, and need each regional relevant departments to coordinate and cooperate to complete. In recent years, Ningbo government speeds up and perfects Development Plan for Ningbo Sea-rail Intermodal Transport, actively introduce preferential support policy, attract customers, expanding the scope of economic hinterland, increase the intensity of canvassing freight, vigorously promote the construction of sea-rail intermodal transport comprehensive experimental area and dry port for Ningbo port, make sure sea and rail transport system healthy and rapid development. At present, Ningbo port has had normal running trains for container sea-rail intermodal transport line 13 and 12 dry port, successively with Yiwu, Jinhua, Quzhou and Nanchang, Shangrao, Yingtan, Xiangyang, Xi 'an, Lanzhou, Xinjiang 20 cities to form sea-rail intermodal transport service network. Ningbo - Jinhua (Yiwu) - Shangrao (in Jiangxi province) trains lines as a demonstration line is actively constructing container sea-rail intermodal transport network demonstration project which affects east China trade area.

Container sea-rail intermodal transport operations of Ningbo port has achieved remarkable achievement, but due to the short development time, the sea-rail intermodal transport volume accounted for the proportion of container throughput is still low, only $0.72 \%$ in 2014 . To optimize the structure of port transport, and develop port services and integrate into the national strategy of "One Belt And One Road" needs to take targeted measures on the basis of predicting development condition.

\section{Modelling}

Grey Model. Grey system theory is developed rapidly after the 1980s and largely used in industry and agriculture, transport, energy and other fields, in order to solve problems which are "denotation unclear, connotation clear" in production, life and scientific research. The first, Grey prediction puts the original data into the grey model for special treatment to reduce data randomness, then sums up potential rules to reasonably predict the development trend of targeted object. Grey model GM $(1,1)$ is the most widely used grey prediction model. Grey accumulated generating operation (Accumulated Generating Operation, AGO) is the important link of Grey model GM $(1,1)$ predicting process, it can make the sequence of increasing over time and has good overall trends and forecasting ability. However, this model is only effective for exponential growth sequence forecasting, and is poor for the randomness sequence. Solving its development parameters a and coordination coefficient b exists theoretical defects that lead big error [6].

In practice, the model form is as follows:

(1) The original data series

$$
x^{(0)}=\left\{x^{(0)}(1), x^{(0)}(2), \ldots, x^{(0)}(n)\right\}
$$

(2) Accumulated generating Operation,

$$
\begin{array}{r}
x^{(1)}=\left\{x^{(1)}(1), x^{(1)}(2), \ldots, x^{(1)}(n)\right\} \# \\
x^{(1)}(k)=\sum_{i=1}^{k} x^{(0)}(i), \mathrm{k}=1,2 \cdots, \mathrm{n}
\end{array}
$$

(3) Constructing the data matrix 


$$
B=\left[\begin{array}{cc}
-\frac{1}{2} x^{(1)}(1)+x^{(1)}(2) & 1 \\
-\frac{1}{2} x^{(1)}(2)+x^{(1)}(3) & 1 \\
-\frac{1}{2} x^{(1)}(n-1)+x^{(1)}(n) & 1
\end{array}\right]
$$

(4) Establishing differential equations

(5) GM(1,1) Model

$$
\begin{gathered}
\frac{d x^{(0)}}{d t}+a x^{(1)}=b \\
\# \hat{a}=\left(\begin{array}{l}
a \\
b
\end{array}\right)=\left(B^{T} \cdot B\right)^{-1} \times B^{T} \times y_{n} \#
\end{gathered}
$$

$$
\begin{aligned}
\hat{x}(k+1) & =\left[x^{(0)}(1)-\frac{b}{a}\right] e^{-a k}+\frac{b}{a} \\
\hat{x}^{(0)}(k) & =\hat{x}^{(1)}(k)-\hat{x}^{(1)}(k-1)
\end{aligned}
$$

$\hat{x}^{(0)}(k)$ is the predictive value of the model.

RBF Neural Network Model. RBF neural network is a kind of nonlinear three layer feed-forward artificial neural network, respectively input layer, RBF neurons in hidden layer and output layer containing linear neurons. Hidden layer is response to input layer signal by nonlinear transformation function, the number of hidden unit bases on actual needs of research question to determine; the output layer is obtained by linear function of hidden unit weighted. RBF neural network can solve local optimal problems of BP neural network, and has advantages of nonlinear mapping ability and good generalization ability and so on [7]. But RBF neural network can't tell reasoning process and the basis, it's essential to lose some information in the process of solving the problem. Its structural model is shown in Fig. 1.

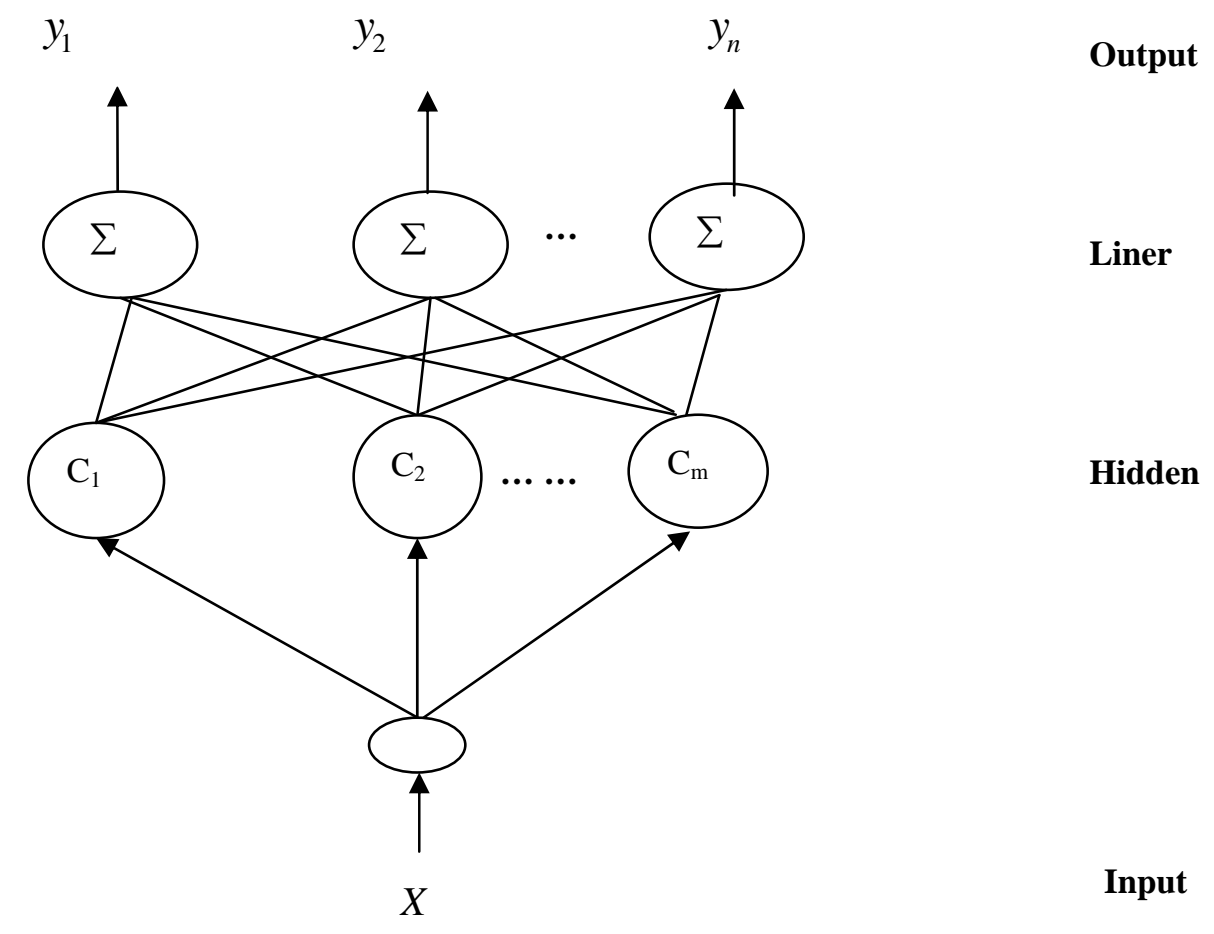

Fig. 1. The structure of RBF neural network model

Grey-RBF Neural Network Combined Forecasting Model. Combination forecasting is more systematic and comprehensive than single model predicts, and much of complementary advantages and disadvantages of each method, so as to effectively reduce interferences from external factors and 
improve prediction accuracy [8]. Grey-RBF neural network combined forecasting model integrates grey model GM $(1,1)$ into RBF neural network through the different form to establish a prediction model. This article selects embedded type grey-RBF neural network combined forecasting model, the model structure is shown in Fig. 2.

Fig. $\quad$ structure of Grey-RBF neural network combined forecasting model

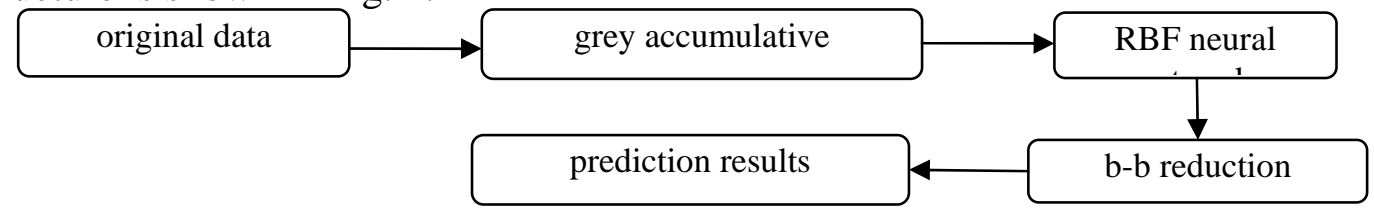

2. The

The model prediction process is that inputting original data through grey (AGO) line link reduces sample data randomness. Secondly, using RBF neural network nonlinear approximation ability to fit and train new data which is accumulative generated to get forecast values, then carrying on the b-b reduction processing and finally outputting prediction results.

\section{Prediction and Results}

Prediction Basis. This paper considers container throughput (TEU), GDP (billion), total goods sent by rail (tons), foreign trade import and export volume (millions of dollars) factors that influence container sea-rail intermodal transport of Ningbo port. The relevant data are from Statistical Yearbook in Ningbo City 2009-2014[9] and National Economic and Social Development Statistics Bulletin in Ningbo City 2009-2014[10] about container sea-rail intermodal transport of Ningbo port and influencing factors, as shown in Table 1.

Table 1. The data of Ningbo port container sea-rail intermodal transport and influencing factors

\begin{tabular}{|l|c|c|c|c|c|c|}
\hline \multicolumn{1}{|c|}{ Year } & 2009 & 2010 & 2011 & 2012 & 2013 & 2014 \\
\hline Container sea-rail intermodal transport volume /TEU & 1690 & 28139 & 46660 & 59470 & 105266 & 135100 \\
\hline Container throughput $/ 10^{4}$ TEU & $\begin{array}{c}1042.3 \\
0\end{array}$ & $\begin{array}{c}1300.3 \\
5\end{array}$ & $\begin{array}{c}1451.2 \\
3\end{array}$ & $\begin{array}{c}1567.1 \\
4\end{array}$ & $\begin{array}{c}1677.4 \\
0\end{array}$ & $\begin{array}{c}1870.0 \\
0\end{array}$ \\
\hline GDP/10 yuan & $\begin{array}{c}4214.6 \\
0\end{array}$ & $\begin{array}{c}5125.8 \\
2\end{array}$ & $\begin{array}{c}6010.4 \\
8\end{array}$ & $\begin{array}{c}6524.7 \\
0\end{array}$ & $\begin{array}{c}7128.8 \\
7\end{array}$ & $\begin{array}{c}7602.5 \\
1\end{array}$ \\
\hline Total goods sent by rail /10 tons & $\begin{array}{c}1705.8 \\
0\end{array}$ & $\begin{array}{c}2059.9 \\
0\end{array}$ & $\begin{array}{c}2168.9 \\
0\end{array}$ & $\begin{array}{c}1924.1 \\
0\end{array}$ & $\begin{array}{c}2168.2 \\
0\end{array}$ & $\begin{array}{c}2364.1 \\
0\end{array}$ \\
\hline Import and export volume/10 ${ }^{9}$ dollars & 608.10 & 829.00 & 981.90 & 965.70 & $\begin{array}{c}1003.3 \\
0\end{array}$ & $\begin{array}{c}1047.0 \\
0\end{array}$ \\
\hline
\end{tabular}

Prediction Results. According to Table 1, the original data of each year, writing matlab programs that correspond to three different forecasting model to train and then fit prediction for container sea-rail intermodal transport capacity of Ningbo port from 2009 to 2014. Fitting forecast values, relative errors and average relative errors are shown in Table 2 and Fig. 3.

Table 2. Relative errors of predicted value for different models

\begin{tabular}{|c|c|c|c|c|c|c|c|c|}
\hline \multicolumn{2}{|c|}{ Year } & 2009 & 2010 & 2011 & 2012 & 2013 & 2014 & $\begin{array}{l}\text { Average } \\
\text { relative }\end{array}$ \\
\hline GM $(1,1)$ & \multirow{3}{*}{$\begin{array}{l}20 \\
0 \\
0.0 \\
0.0 \\
0 \\
0 \\
0 \\
0 \\
0 \\
0 \\
0\end{array}$} & 0 & 9.59 & 4.07 & 9.24 & 10.43 & 1.3 & 6.93 \\
\hline $\mathrm{RBF}$ & & - & 0.03 & 4.12 & 8.65 & 4.98 & 1.5 & 3.85 \\
\hline Grey-RBF & & - & 2.86 & 5.2 & 5.18 & 2.44 & 1.17 & 3.37 \\
\hline
\end{tabular}




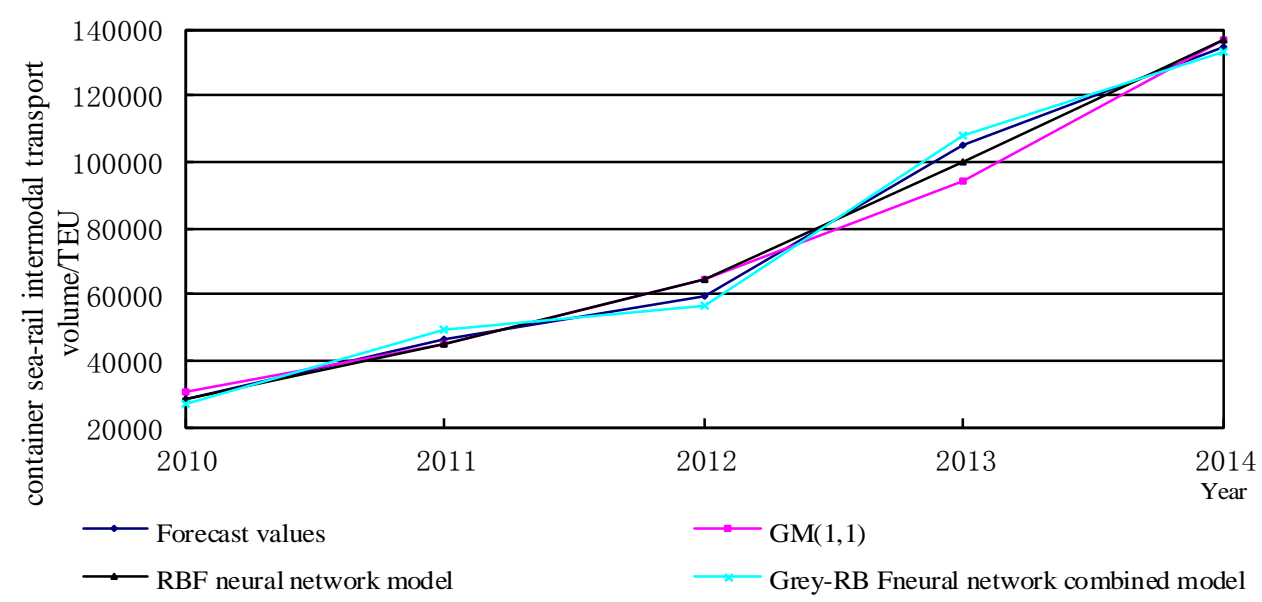

Fig. 3. 2010-2014 container sea-rail intermodal transport forecast capacity of Ningbo port for different forecasting model

From the above chart, the minimum relative error of the actual and estimated values is $1.30 \%$ in Grey Model GM $(1,1)$, the maximum relative error is $10.43 \%$, the average relative error is $6.93 \%$; the actual and estimated values of the minimum relative error is $0.03 \%$ in RBF neural network model, the maximum relative error is $8.65 \%$, the average relative error is $3.85 \%$; the actual and estimated values of the minimum relative error is $8.65 \%$ in Grey-RBF neural network combined forecasting model, the maximum relative error is $1.17 \%$, the average relative error is $3.37 \%$. Three kinds of model fitting prediction results conform to the requirements of the precision, and compared with single forecast model, grey-RBF neural network combined forecasting model has obvious advantages in the container sea-rail intermodal transport capacity forecasts. Table 3 shows container sea-rail intermodal transport capacity of Ningbo port in the next two years using grey-RBF neural network combined forecasting model. The results show that it will continue rapid growth trend in the next two years.

Table 3. 2015-2016 container sea-rail intermodal transport forecast capacity of Ningbo port

\begin{tabular}{|c|c|c|}
\hline Year & 2015 & 2016 \\
\hline $\begin{array}{c}\text { container sea-rail intermodal } \\
\text { transport volume } / \text { TEU }\end{array}$ & 198457 & 287497 \\
\hline
\end{tabular}

Combined related data in Table 1 and Table 3, it can be seen that container sea-rail intermodal transport capacity of Ningbo port presents the characteristics of low base and growing faster. Thanks to attach great importance to develop sea-rail intermodal transport for Ningbo government, and implement supporting policies for container sea-rail intermodal transport over three years, and support Ningbo government in grouping with Ningbo week and other activities, carry on the strategy of dry port, boosting the development and construction of multimodal international hub and sea-rail intermodal transport demonstration project, and strive to set up national sea-rail transport comprehensive experimental area to realize the seamless connection among customs, ports, railways and online achieve acceptance, operation, query, trading , payment functions and mutual benefit and win-win.

\section{Conclusion}

In this paper, grey-RBF neural network combined forecasting model relatively accurate predicts container sea-rail intermodal transport of Ningbo port, achieved the expected goals. Besides this paper considers the four main factors, there are many factors that can influence container sea-rail intermodal transport, and other direct and indirect factors. Meanwhile, the impact degree and priorities will also be different with the passage of time. Therefore, to accurately judge the trend of 
container sea-rail intermodal transport volume growth must select the appropriate optimization prediction model to improve the prediction precision. Ningbo port is active docking "One Belt And One Road" national strategy and the Yangtze River economic belt development opportunity, and together with relevant enterprises to expand sea-rail intermodal transport business, promote port and railway complementary advantages, expand the inland and sea-rail intermodal transport logistics corridor, perfect service functions and build international hub. Under the background of changing in the current economic environment, container throughput and sea-rail intermodal transport volume of Ningbo port will be maintained good momentum.

\section{Acknowledgements}

The research work was supported by the Project of Zhejiang Soft Science (2015C25039).

\section{References}

[1] Leyun Ling. Ningbo sea-rail intermodal transport status and development countermeasures [j]. Water Management, 2013, 10:19-23.

[2] Guanwei Wang, Chun Wang. Container rail-sea intermodal transport volume forecasting based on grey system theory [j]. Containerization, 2008, 05:20-22.

[3] Huirong Wu, Xiaoning Zhu, Jifeng Qian. Container sea-rail intermodal volume forecasting based on system dynamics [j].LogisticsTechnology,2012,17:205-207+230.

[4] Jinghai Chen. Qingdao port container sea-rail intermodal transport based on transport volume forecasting and benefit analysis [d]. Ocean University of China, 2013.

[5] Yanqin Chen. Container rail-sea intermodal transport volume forecasting based on gray theory and BP network [j]. China Shipping (next fortnightly), 2010, 12:74-76.

[6] Wen Long, Songjin Xu. Urban water consumption forecasting based on Grey- RBF combination model [j]. Water Technologies, 2011, 04:34-37.

[7] Long Jiang, Jiajia Xue. Stock price prediction based on differential Grey-RBF network model [j]. Journal of Guangxi University of Technology (natural science Edition), 2012, 03:594-599.

[8] Xiaoyin Wang. Prediction of railway freight volume based on RBF neural network of grey system theory[j]. Journal of Gansu Radio and TV University, 2012, 03:38-41.

[9] Statistical Yearbook in Ningbo City, 2009-2014.

[10] National Economic and Social Development statistics Bulletin in Ningbo City, 2009-2014. 